\title{
Expression of miRNA in 5-FU resistant esophageal cancer
}

\author{
PRASIT MAHAWONGKAJIT and PRAKITPUNTHU TOMTITCHONG
}

Department of Surgery, Faculty of Medicine, Thammasat University, Amphur Klongluang, Pathumthani 12120, Thailand

Received December 10, 2019; Accepted May 4, 2020

DOI: $10.3892 / \mathrm{mco} .2020 .2070$

\begin{abstract}
Fluoropyrimidine plus platinum (FP) are chemotherapeutic drugs that are most frequently used to treat esophageal squamous cell carcinoma (ESCC). However, drug resistance often occurs, and the mechanisms of resistance to $5-\mathrm{FU}$ is yet to be determined. The role of micro (mi)RNAs has been well established in a variety of human cancers. The aim of the present study was to investigate the expression profile of ESCC, revealing the differential expression between ESCC and 5-FU resistant ESCC. The establishment of a 5-FU resistant (5-FUR) cell lines model provides a way of analyzing the expression of miRNAs in drug resistance. The miRNA expression indicated 50 miRNAs that were upregulated in TE10-5-FUR compared with TE10, while 119 miRNAs were downregulated. The TE11-5-FUR demonstrated 140 miRNAs were upregulated compared with TE11, which exhibited 12 downregulated miRNAs. Both cell lines share the 2 candidate upregulated miRNAs (miR-146a and miR-483-5p) and 5 downregulated miRNAs (miR-34a, miR-141, miR-200b, miR-200c and miR-205). Further studies are required to analyze and evaluate the function of the miRNAs.
\end{abstract}

\section{Introduction}

Cancer is a leading cause of human death. Esophageal cancer is the nine most common cancer worldwide, with an estimated 572,034 new cases and 508,585 deaths in 2018. Men have a substantially higher incidence than women (1). The cancers arise from the esophageal mucosa. There are two main histological types: Esophageal squamous cell carcinoma (ESCC) and esophageal adenocarcinoma (EAC). ESCC is the predominant histological type in southeast Asian countries, including Thailand (2). Major risk factors for ESCC are smoking and excessive alcohol consumption $(3,4)$. These risk factors may

Correspondence to: Dr Prasit Mahawongkajit, Department of Surgery, Faculty of Medicine, Thammasat University (Rangsit Campus), 99/209 Moo 18, Paholyothin Road, Amphur Klongluang, Pathumthani 12120, Thailand

E-mail: prasit_md@yahoo.com

Key words: microRNA, 5-FU resistant, esophageal squamous carcinoma cell lead to esophageal cancer through multiple genetic alterations, such as activated oncogenes and inhibited tumor suppressor genes (5).

Despite recent advances in surgical techniques and perioperative management, the prognosis of patients who undergo surgery alone for esophageal cancer remains poor. Neoadjuvant chemotherapy and chemoradiotherapy followed by surgery have emerged as a promising strategy for advanced esophageal cancer, and, in fact, good responders to such preoperative therapy show improved survival (6-9). Cisplatin/5-fluorouracil (5-FU) has been accepted as a standard treatment in for ESCC (10). However, following Cisplatin/5-FU based chemotherapy, non-responders are likely to receive no survival benefit $(11,12)$. The ability to predict the response to chemotherapy before treatment should limit the application of chemotherapy to selected ESCC patients who are likely to show benefits. However, the prognosis of patients who are resistant to 5-FU treatment is poor. Resistance to treatment with anticancer drugs results from a variety of factors, including individual variations in patients.

miRNAs are noncoding RNAs that are approximately 22 nucleotides in length. They act through repressing the translation of target mRNAs by binding to the 30-nucleotide untranslated region of those mRNAs (13). miRNAs exist stably in various tissues and play pivotal roles in differentiation and development $(14,15)$. The role of miRNAs has been well established in various human cancers. The evidence has shown that miRNA mutations or misexpression correlates with various human cancers, indicating that miRNAs can function as tumor suppressors or oncogenes. In addition, aberrant expression of miRNAs has been reported in various types of cancers $(16,17)$. Recent studies of ESCC reported the oncogenic microRNAs: miR-21, miR-10b, miR-31, and miR-373; the oncosuppressor microRNAs: let-7, miR-34a, miR-133a, miR-150, miR-375, miR-205, miR-145, miR-29c, and miR-210 (18). The mi-R-25, miR-99a, miR-133a and miR-133b showed good potential as diagnostic markers and interestingly the mi-R-21, miR-27b, miR-126, miR-143 and miR-145 appeared to be useful both as diagnostic and prognostic/predictive markers (19). A recent publication showed the involvement of several miRNAs in resistance to 5-FU treatment as follows: The miRNA profiles of neoadjuvant radiochemotherapy non-responders showed upregulation of has-miR-1323, has-miR-3678-3p, hsv2miR-H7-3p, has-miR-194, has-miR-3152, kshv-miR-K12-4-3p, has-miR-665 and has-miR-3659, and downregulation of has-miR-126, has-miR-484, has-miR-330-3p and has-miR-3653 (20). The aim of this study was to investigate 
the expression profile of ESCC, revealing differential expression between ESCC and 5-FU resistant ESCC.

\section{Materials and methods}

Cell lines and cell culture. Human ESCC cell lines (TE4, TE10, TE11 and TE15) were obtained from Tohoku University. All cells were cultured in Dulbecco's Modified Eagle's Medium (DMEM) (Nacalai Tesque, Inc.) containing 10\% fetal bovine serum (Life Technologies Inc.), 10\% penicillin/streptomycin (100 U/ml penicillin and $100 \mu \mathrm{g} / \mathrm{ml}$ streptomycin) (Nacalai Tesque, Inc.) in a humidified atmosphere under $5 \% \mathrm{CO}_{2}$ at $37^{\circ} \mathrm{C}$.

Establishment of 5-FU resistant cell lines. 5-FU resistant (5-FUR) cell lines were cultured through gradual increases in 5-FU concentration. The cultured cells were exposed to 5-FU at an initial concentration of $1 \mathrm{nM} / \mathrm{ml}$. After $24 \mathrm{~h}$, the cells were cultured in 5-FU free medium until confluence. Next, 5 -FU concentrations were increased by 2 - to 3 -fold and the cycle was repeated.

Proliferation assay. The WST-8 (2-(2-methoxy-4-nitrphenyl)3-(4-nitrophenyl)-5-(2,4-disulfophenyl)-2H-tetrazolium, monosodium salt) assay was conducted as described by the manufacturer (Nacalai Tesque Inc.) and was used to determine the $\mathrm{IC}_{50}(50 \%$ growth inhibition concentration) value of $5-\mathrm{FU}$. Cells were plated in 96-well microplates and cultured for $12 \mathrm{~h}$ before exposure to various concentrations of 5-FU $(0,0.5$, $1,5,10,50 \mu \mathrm{g} / \mathrm{ml}$ ) for $48 \mathrm{~h}$. The optical density (OD) value was detected by RAINBO SUNRISE (Wako Pure Chemical Industries Ltd.) at $450 \mathrm{~nm}$ test wavelength and $650 \mathrm{~nm}$ reference wavelength. The $\mathrm{IC}_{50}$ value of 5-FU was calculated from the dose-response curve.

Isolation of miRNA and miRNA microarray. The miRNA was isolated from the cell lines using the mirVana ${ }^{\mathrm{TM}}$ miRNA Isolation kit according to the manufacturer's protocol (Ambion; Thermo Fisher Scientific, Inc.). The concentration of RNA was quantified using the NanoDrop ND-1000 spectrophotometer (Thermo Fisher Scientific, Inc.). The miRNA expression profiling of human ESCC cell lines (TE10, TE11) and their corresponding 5-FU resistant (5-FUR) daughter lines (TE10 5-FUresistant cells: TE10-5-FUR; TE11 5-FU resistant cell: TE11-5-FUR) were examined by TaqMan ${ }^{\circledR}$ Human MicroRNA Array (Applied Biosystems; Thermo Fisher Scientific, Inc.). It contained 384 miRNA targets (and 7 control miRNAs) and was performed using Megaplex ${ }^{\mathrm{TM}}$ RT Primers. The miRNA microarray analysis was performed with Applied Biosystems 7900HT fast real-time PCR System and RT-PCR StatMiner ${ }^{\mathrm{TM}}$ software. The expression of each miRNA in 5-FU resistant cell lines was compared with that in the control parental cell line, and the ratio of miRNA expression in 5-FU resistant cells to control cells was calculated for all 384 miRNAs.

Statistical analysis. The significance validation data of miRNA expression are expressed as mean \pm standard error of the mean. The cell viability is computed and differences between viability curves are compared. The parameters are compared using the $\chi^{2}$ test for categorical data and continuous variables are compared using Student's t-test. All data were analyzed with SPSS 22.0 data (IBM Corp.). A P-value $<0.05$ was considered to be statistically significant.

\section{Results}

The study first established 5-FU resistant ESCC cell lines (TE4, TE10, TE11 and TE15) by gradually increasing 5-FU concentration (starting from $0.1 \mu \mathrm{g} / \mathrm{ml}$ ) and evaluating the cultures by WST- 8 assay every 4 weeks. After 8 weeks, we determined the $\mathrm{IC}_{50}$ values. The results showed a significant fold-increase in the concentration of 5-FU that inhibited TE10 and TE11 cell growth by 50\%. TE10-5-FUR cells were relatively resistant to $5-\mathrm{FU}$, with an $\mathrm{IC}_{50}$ of $42.66 \pm 2.38 \mu \mathrm{g}$ compared to a value of $4.08 \pm 2.06 \mu \mathrm{g}$ in the parent cells, a 10.5-fold increase in concentration $(\mathrm{P}<0.01)$. TE11-5-FUR cells were also relatively resistant to $5-\mathrm{FU}$ with an $\mathrm{IC}_{50}$ of $21.62 \pm 11.91 \mu \mathrm{g}$ compared to $2.73 \pm 0.81 \mu \mathrm{g}$ in TE11 parent cells, a 7.91-fold increase $(\mathrm{P}<0.01)$ (Fig. 1).

To assess miRNA expression levels, we used miRNA microarray to evaluate both 5-FU resistant and wild-type ESCC cell lines. The results of the miRNA expression study were subjected to a differential expression analysis and visualized using Expression Suite Software (Applied Biosystems; Thermo Fisher Scientific, Inc.). The analysis showed 50 miRNAs upregulated in TE10-5-FUR compared to TE10, while 119 miRNAs were downregulated. The TE11-5-FUR demonstrated 140 miRNAs upregulated compared to TE11 with 12 miRNAs were downregulated. Among the most significantly upregulated miRNAs of TE10-5-FUR were has-miR-99a-4373008, has-miR-100-4373160, has-miR-125b-4373148, has-miR-140-5p-437374, has-miR-146a-4373132, has-miR-155-4375459, has-miR-196b-4395326, has-miR-302b-4378071, has-miR-499a-4373207, has-miR-483-5p-4395449 while the most downregulated were has-miR-34a-4395168, has-miR-130a-4373145, has-miR-141-4373137, has-miR-152-4395170, has-miR-183-4395380, has-miR-200a-4378069, has-miR-200b-4395362, has-miR-200c-4395411, has-miR-205-4373093, has-miR-429-4373203 (Table I). For TE11-5-FUR, the prominent upregulated miRNAs were has-miR-let7b-4395446, has-miR-let7c-4373167, has-miR-10b-4395329, has-miR-22-4373079, has-miR-137-4373301, has-miR-146a-4373132, has-miR-296-5p-4373066, has-miRs-449b-4381011, has-miR-483-5p-4395449, has-miR-522-4395524, while all those downregulated were has-miR-18a-4395533, has-miR-34a-4395168, has-miR-141-4373137, has-miR-200b-4395362, has-miR-200c-4395411, has-miR-203-4373095, has-miR-205-4373093, has-miR-331-5p-4395344, has-miR-429-4373203, has-miR-708-4395452 (Table II). The result in both cell lines observed at intersection of 2 miRNAs upregulated (miR-146a and miR-483-5p) and 5 miRNAs downregulated (miR-34a, miR-141, miR-200b, miR-200c and miR-205) (Fig. 2). Identification of potential target genes of miRNAs associated with 5-FU resistant ESCC cell lines was essential to investigate their biological functions. Candidate miRNAs of both cell lines were reviewed using the database of miRNA.org site (http://www.microrna.org) (21). 
Table I. The list of differentially expressed microRNAs in TE10-5-FUR vs. TE10.

\begin{tabular}{|c|c|c|c|}
\hline miRNAs & Fold-change & Regulation & microRNA family \\
\hline has-miR-99a-4373008 & 5.25707 & Up & miR-99a \\
\hline has-miR-100-4373160 & 3.79643 & Up & miR-100 \\
\hline has-miR-125b-4373148 & 4.09845 & Up & $\operatorname{miR}-125 b$ \\
\hline has-miR-140-5p-437374 & 3.76036 & Up & miR-140-5p \\
\hline has-miR-146a-4373132 & 5.46298 & Up & miR-146a \\
\hline has-miR-155-4375459 & 4.67046 & $\mathrm{Up}$ & $\operatorname{miR}-155$ \\
\hline has-miR-196b-4395326 & 6.09578 & Up & miR-196b \\
\hline has-miR-302b-4378071 & 4.67347 & Up & $\operatorname{miR}-302 b$ \\
\hline has-miR-499a-4373207 & 5.78943 & Up & $\operatorname{miR}-499 a$ \\
\hline has-miR-483-5p-4395449 & 4.54962 & Up & $\operatorname{miR}-483-5 p$ \\
\hline has-miR-34a-4395168 & 3.08635 & Down & miR-34a \\
\hline has-miR-130a-4373145 & 1.87463 & Down & miR-130a \\
\hline has-miR-141-4373137 & 2.98572 & Down & miR-141 \\
\hline has-miR-152-4395170 & 0.56493 & Down & miR-152 \\
\hline has-miR-183-4395380 & 1.59869 & Down & $\operatorname{miR}-183$ \\
\hline has-miR-200a-4378069 & 2.78942 & Down & miR-200a \\
\hline has-miR-200b-4395362 & 0.89423 & Down & $\operatorname{miR}-200 b$ \\
\hline has-miR-200c-4395411 & 2.05483 & Down & $\operatorname{miR}-200 \mathrm{c}$ \\
\hline has-miR-205-4373093 & 1.68473 & Down & miR-205 \\
\hline has-miR-429-4373203 & 1.87439 & Down & $\operatorname{miR}-429$ \\
\hline
\end{tabular}

miR, microRNA.
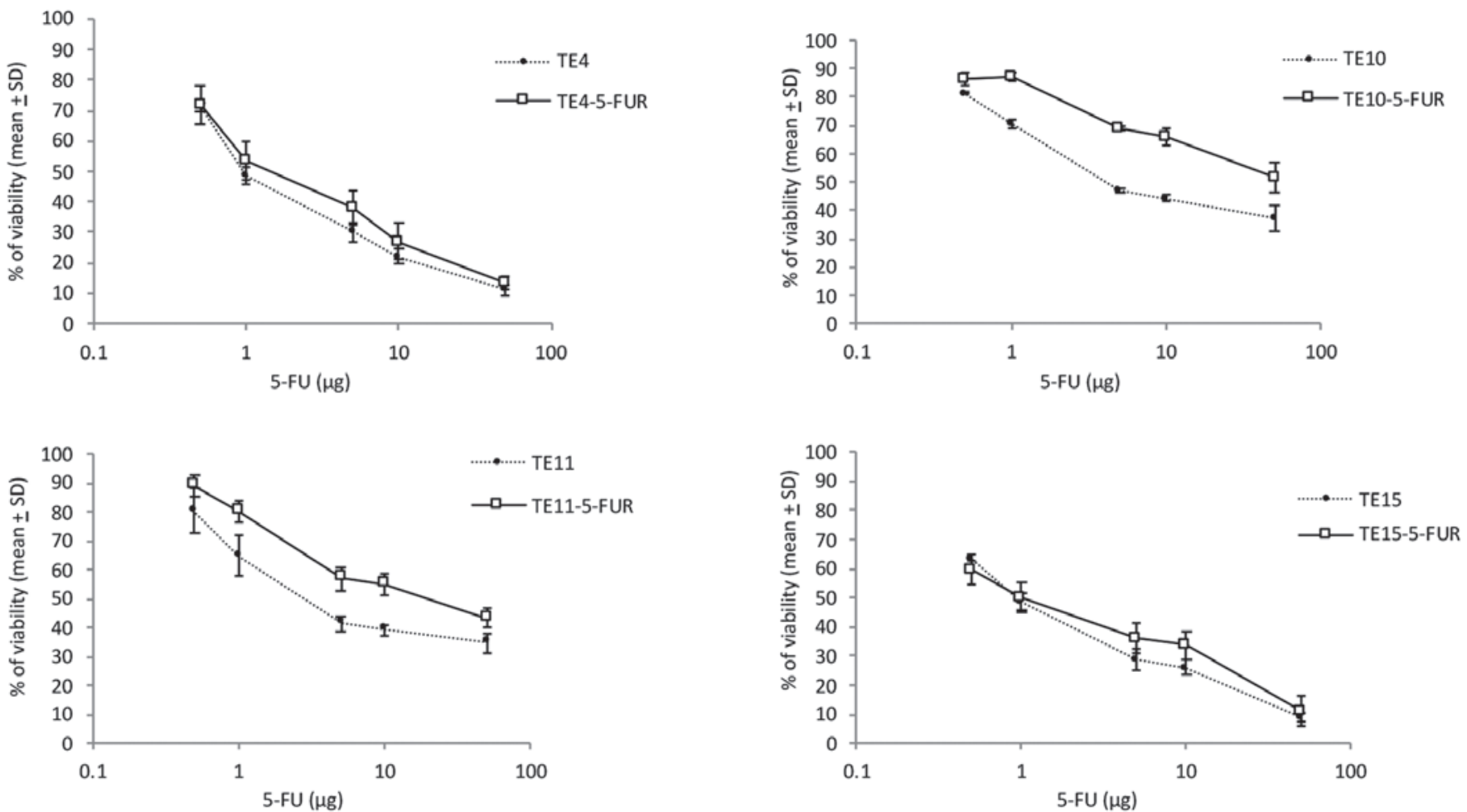

Figure 1. Quantitation of 5-FU resistance of esophageal squamous cell lines. TE4, TE4-5-FUR, TE10, TE10-5-FUR, TE11, TE11-5-FUR, TE15 and TE15-5-FUR cells were seeded into 96 -well microplates $\left(5 \times 10^{3}\right.$ per well) $12 \mathrm{~h}$ before treatment and were then exposed to different concentrations $(0,0.5,1,5$, 10 and $50 \mu \mathrm{g}$ ) of 5-FU for $48 \mathrm{~h}$. The percentage of cellular proliferation was evaluated with WST-8. The 5-FU resistant TE10-5-FUR cells showed resistance to 5-FU with an $\mathrm{IC}_{50}$ value of $42.66 \pm 2.38 \mu \mathrm{g}$ and TE11-5-FUR achieved an $\mathrm{IC}_{50}$ value of $21.62 \pm 11.91 \mu \mathrm{g}$, both $\mathrm{P}<0.01$ compared to their parental cells. For 5-FU resistant TE4-5-FUR cells and TE15-5-FUR, the results were not difference to their parental cells. Data are presented as means \pm SD and evaluated using Student's t-test. WST-8, 2-(2-methoxy-4-nitrophenyl)-3-(4-nitrophenyl)-5-(2,4-disulfophenyl)-2H-tetrazolium, monosodium salt; SD, standard deviation. 
Table II. The list of differentially expressed microRNAs in TE11-5-FUR vs. TE11.

\begin{tabular}{|c|c|c|c|}
\hline miRNAs & Fold-change & Regulation & microRNA family \\
\hline has-miR-let7b-4395446 & 6.43275 & Up & let7b \\
\hline has-miR-let7c-4373167 & 7.59883 & Up & let7c \\
\hline has-miR-10b-4395329 & 5.58848 & $\mathrm{Up}$ & $\mathrm{miR}-10 \mathrm{~b}$ \\
\hline has-miR-22-4373079 & 6.15343 & Up & miR-22 \\
\hline has-miR-137-4373301 & 5.42084 & Up & $\operatorname{miR}-137$ \\
\hline has-miR-146a-4373132 & 5.58873 & Up & miR-146a \\
\hline has-miR-296-5p-4373066 & 5.02579 & Up & miR-296-5p \\
\hline has-miR-449b-4381011 & 4.96571 & Up & $\operatorname{miR}-449 b$ \\
\hline has-miR-483-5p-4395449 & 6.19015 & Up & miR-483-5p \\
\hline has-miR-522-4395524 & 7.06593 & Up & miR-522 \\
\hline has-miR-18a-4395533 & 0.47938 & Down & $\operatorname{miR}-18 \mathrm{a}$ \\
\hline has-miR-34a-4395168 & 0.30295 & Down & $\operatorname{miR}-34 a$ \\
\hline has-miR-141-4373137 & 3.15697 & Down & miR-141 \\
\hline has-miR-200b-4395362 & 3.18372 & Down & miR-200b \\
\hline has-miR-200c-4395411 & 4.10116 & Down & miR-200c \\
\hline has-miR-203-4373095 & 0.73426 & Down & miR-203 \\
\hline has-miR-205-4373093 & 1.49047 & Down & miR-205 \\
\hline has-miR-331-5p-4395344 & 0.80691 & Down & miR-331-5p \\
\hline has-miR-429-4373203 & 3.88948 & Down & miR-429 \\
\hline has-miR-708-4395452 & 0.56551 & Down & miR-708 \\
\hline
\end{tabular}

miR, microRNA.

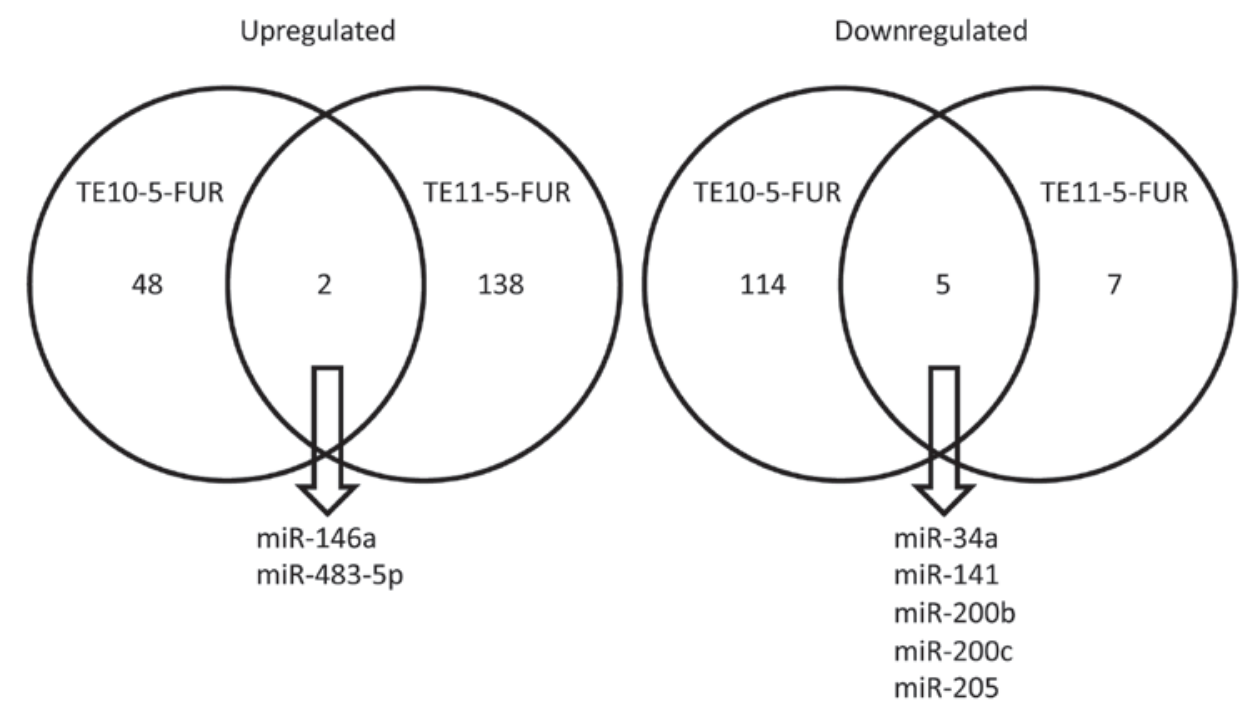

Figure 2. Diagrams of differentially expressed miRNAs shared between 5-FU resistance esophageal squamous cell carcinoma. The results demonstrated 50 miRNAs upregulated and 119 miRNAs downregulated in TE10-5-FUR, 140 miRNAs upregulated and 12 miRNAs downregulated in TE11-5-FUR, compared to their wild type. Both cell lines share the 2 candidate miRNAs upregulated (miR-146a and miR-483-5p) and 5 miRNAs were downregulated (miR-34a, miR-141, miR-200b, miR-200c and miR-205). miRNA/miR, microRNA.

\section{Discussion}

Esophageal cancer is a major global health problem. Squamous cell carcinoma is the main histological type. Current management of ESCC depends on the stage of the disease and includes surgery, chemotherapy and radiation therapy. In multimodal treatment of esophageal cancer, chemotherapy has an important role in combination with radiation therapy and/or surgery. Fluoropyrimidine plus platinum (FP) are the chemotherapeutic drugs most frequently used to treat ESCC. This regimen has been reported to be effective, with improved overall survival $(22,23)$. However, drug resistance 
often occurs, and the mechanisms of resistance to 5-FU are still not clear.

The establishment of 5-FU resistant (5-FUR) cell lines model provides an approach to analyze the mechanism of drug resistance. The resistant cells were created from their parental lines by exposing them to gradually increasing 5-FU concentrations for 2 months. The TE10-5-FUR and TE11-5-FUR lines were partially resistant to 5 -FU with $\mathrm{IC}_{50}$ values of $42.66 \pm 2.38 \mu \mathrm{g}$ and $21.62 \pm 11.91 \mu \mathrm{g}$.

miRNAs are short noncoding RNAs that regulate gene expression and play an important role in human cancers. They can also modulate the sensitivity and resistance to anticancer drugs. This study demonstrated 50 miRNAs upregulated and 119 miRNAs downregulated in TE10-5-FUR, 140 miRNAs upregulated and 12 miRNAs downregulated in TE11-5-FUR, compared to their wild type. The result in both of cell lines found 2 candidate miRNAs upregulated (miR-146a and miR-483-5p) and 5 miRNAs were downregulation (miR-34a, miR-141, miR-200b, miR-200c and miR-205). Recent studies also showed the involvement of several miRNAs in resistance to anticancer treatment and roles in esophageal cancer. miR-146a has been reported as perhaps being associated with the cisplatin-base susceptibility to lung cancer by downregulating cyclin $\mathrm{J}(23,24)$ and as a potential therapeutic target for multidrug-resistant lung cancer by targeting DNA damage inducible transcript 3 (25). Polymorphism in miR-146a could be associated with the lymph node metastasis and prognosis of gastric cancer patients treated with oxaliplatin and fluoropyrimidines (26). miR-483-5p has been described upregulation with might be a tumor promoter of ESCC that correlated with TNM stage and survival (27). miR-483-5p could inhibit mitochondrial fission protein FIS1 with significant association with cisplatin sensitivity and with overall survival (28). miR-34a showed significantly expressed reduction in ESCC tissues and exerted its anticancer function by suppressing PLCE1 (29). miR-34a has shown upregulation in cisplatin sensitivity for lung cancer treatment via p53/ miR-34a/MYCN axis (30), mediates oxaliplatin resistance of colorectal cancer cells by inhibiting macroautophagy via the TGF- $\beta /$ Smad4 pathway (31) and the patients with high levels of expression were found to benefit more from 5-FU based chemotherapy than patients with low levels of expression with the potential targets including CREB1, Bcl-2, Notch 1, Sirt1, and E2F3 (32). For miR-141, the overexpression could abolish the self-renewal ability and carcinogenicity of esophageal cancer stem-like cells and decrease cell invasion and migration by suppressing TM4SF1 (33). It enhanced the effected of 5-FU and suppressed the malignant biological behaviors of colorectal cancer by MAP4K4 signaling pathway (34). miR-141 was significantly decreased and correlated with advanced TNM stage and lymph node metastasis with predicted possible target MACC1 in gastric cardia adenocarcinoma (35). miR-200b has been reported down-regulated in the multi-drug resistance of small cell lung cancer via ZEB2 (36). For miR-200c, the serum levels in advanced ESCC patients were significantly increased and associated with poor outcome of platinum-based chemotherapy (37). miR-200c also related to 5-FU chemotherapy with the potential targets PTEN and E-cadherin in colorectal cancer (38-40). miR-205 has been published as a tumor suppressor in adenocarcinoma and an oncogene in squamous cell carcinoma of esophagus through regulation of epithelial-mesenchymal transition (EMT) (41) and the Sp1-mediated transcriptional activation of miR-205 promotes radioresistance through PTEN via PI3K/AKT pathway in ESCC (42). For TE11-5-FUR, the let-7b and let-7c demonstrated upregulation with related to the previous publication that reported the let7 play the role of oncosuppressor microRNAs (18).

This study acknowledges its own limitations-the study, the sample size is too small to make any reasonable conclusion. The cell viability and miRNA microarray experiments are not performed on non-cancer cell lines as a control. This study is not verified the function analysis of miRNAs that have related to resistance to 5-FU. Their function should be testing by gene transfer or knockdown with in vitro studies. Alternatively, the association of these miRNAs with clinical efficacy of chemotherapy be examining in a cohort of patients with esophageal cancer. The current study revealed differentially regulated miRNAs that are involved in 5-FU resistant ESCC. The identification of miRNA expression profiles and candidates in 5-FU resistant ESCC could provide a better understanding of the mechanisms involved in chemo-sensitivity or resistance. By predicting the response to chemotherapy, one could offer another treatment option for patients who would otherwise be resistant. Further study is needed to select the potential targets and explore the pathways that are upregulated or downregulated after induction of 5-FU therapy. Moreover, these findings suggest that it may be helpful to develop novel strategies for targeted therapies in ESCC patients.

\section{Acknowledgements}

Not applicable.

\section{Funding}

This research supported in part by Thammasat University.

\section{Availability of data and materials}

The datasets used and/or analyzed during the present study are available from the corresponding author on reasonable request.

\section{Authors' contributions}

PM and PT contributed to the conception and design of the study. PM contributed to data collection, conduction of the study, performed the experiments, analysis and interpretation of the data. PM and PT reviewed the manuscript, designed the figures and tables. All the authors have read and approved the final version of this manuscript.

\section{Ethics approval and consent to participate}

Not applicable.

\section{Patient consent for publication}

Not applicable. 


\section{Competing interests}

The authors declare that they have no competing interests.

\section{References}

1. Bray F, Ferlay J, Soerjomataram I, Siegel RL, Torre LA and Jemal A: Global cancer statistics 2018: GLOBOCAN estimates of incidence and mortality worldwide for 36 cancers in 185 countries. CA Cancer J Clin 68: 394-424, 2018.

2. Nun-Anan $P$ and Vilaichone RK: Late stage and grave prognosis of esophageal cancer in Thailand. Asian Pac J Cancer Prev 16: $1747-1749,2015$.

3. Morita M, Kumashiro R, Kubo N, Nakashima Y, Yoshida R, Yoshinaga K, Saeki H, Emi Y, Kakeji Y, Sakaguchi Y, et al: Alcohol drinking, cigarette smoking, and the development of squamous cell carcinoma of the esophagus: Epidemiology, clinical findings, and prevention. Int J Clin Oncol 15: 126-134, 2010.

4. Toh Y, Oki E, Ohgaki K, Sakamoto Y, Ito S, Egashira A, Saeki H, Kakeji Y, Morita M, Sakaguchi Y, et al: Alcohol drinking, cigarette smoking, and the development of squamous cell carcinoma of the esophagus: Molecular mechanisms of carcinogenesis. Int J Clin Oncol 15: 135-144, 2010.

5. Huang FL and Yu SJ: Esophageal cancer: Risk factors, genetic association, and treatment. Asian J Surg 41: 210-215, 2018.

6. Hsu PK, Chen HS, Huang CS, Liu CC, Hsieh CC, Hsu HS, Wu YC and Wu SC: Patterns of recurrence after oesophagectomy and postoperative chemoradiotherapy versus surgery alone for oesophageal squamous cell carcinoma. Br J Surg 104: 90-97, 2017.

7. Pasquali S, Yim G, Vohra RS, Mocellin S, Nyanhongo D, Marriott P, Geh JI and Griffiths EA: Survival after neoadjuvant and adjuvant treatments compared to surgery alone for resectable esophageal carcinoma: A network meta-analysis. Ann Surg 265: 481-491, 2017.

8. Ando N, Iizuka T, Ide H, Ishida K, Shinoda M, Nishimaki T, Takiyama W, Watanabe H, Isono K, Aoyama N, et al: Surgery plus chemotherapy compared with surgery alone for localized squamous cell carcinoma of the thoracic esophagus: A Japan clinical oncology group study-JCOG9204. J Clin Oncol 21: 4592-4596, 2003.

9. Ando N, Kato H, Igaki H, Shinoda M, Ozawa S, Shimizu H, Nakamura T, Yabusaki H, Aoyama N, Kurita A, et al: A randomized trial comparing postoperative adjuvant chemotherapy with cisplatin and 5-fluorouracil versus preoperative chemotherapy for localized advanced squamous cell carcinoma of the thoracic esophagus (JCOG9907). Ann Surg Oncol 19: 68-74, 2012.

10. Haisley KR, Hart KD, Nabavizadeh N, Bensch KG, Vaccaro GM, Thomas CR Jr, Schipper PH, Hunter JG and Dolan JP: Neoadjuvant chemoradiotherapy with concurrent cisplatin/5-fluorouracil is associated with increased pathologic complete response and improved survival compared to carboplatin/paclitaxel in patients with locally advanced esophageal cancer. Dis Esophagus 30: 1-7, 2017.

11. Rumiato E, Cavallin F, Boldrin E, Cagol M, Alfieri R, Basso D, Castoro C, Ancona E, Amadori A, Ruol A and Saggioro D: ERCC1 C8092A (rs3212986) polymorphism as a predictive marker in esophageal cancer patients treated with cisplatin/5-FU-based neoadjuvant therapy. Pharmacogenet Genomics 23: 597-604, 2013.

12. Miyata H, Yoshioka A, Yamasaki M, Nushijima Y, Takiguchi S, Fujiwara Y, Nishida T, Mano M, Mori M and Doki Y: Tumor budding in tumor invasive front predicts prognosis and survival of patients with esophageal squamous cell carcinomas receiving neoadjuvant chemotherapy. Cancer 115: 3324-3334, 2009.

13. Bartel DP: MicroRNAs: Genomics, biogenesis, mechanism, and function. Cell 116: 281-297, 2004.

14. Croce CM and Calin GA: miRNAs, cancer, and stem cell division. Cell 122: 6-7, 2005.

15. Chakraborty C, Chin KY and Das S: miRNA-regulated cancer stem cells: Understanding the property and the role of miRNA in carcinogenesis. Tumour Biol 37: 13039-13048, 2016.

16. Barbato S, Solaini G and Fabbri M: MicroRNAs in oncogenesis and tumor suppression. Int Rev Cell Mol Biol 333: 229-268, 2017

17. Svoronos AA, Engelman DM and Slack FJ: OncomiR or tumor suppressor? The duplicity of microRNAs in cancer. Cancer Res 76: 3666-3670, 2016.
18. Hemmatzadeh M, Mohammadi H, Karimi M, Musavishenas MH and Baradaran B: Differential role of microRNAs in the pathogenesis and treatment of esophageal cancer. Biomed Pharmacother 82: 509-519, 2016.

18. Sakai NS, Samia-Aly E, Barbera M and Fitzgerald RC: A review of the current understanding and clinical utility of miRNAs in esophageal cancer. Semin Cancer Biol 23: 512-521, 2013.

19. Hummel R, Sie C, Watson DI, Wang T, Ansar A, Michael MZ, Van der Hoek M, Haier J and Hussey DJ: MicroRNA signatures in chemotherapy resistant esophageal cancer cell lines. World J Gastroenterol 20: 14904-14912, 2014.

20. Slotta-Huspenina J, Drecoll E, Feith M, Habermehl D, Combs S, Weichert W, Bettstetter M, Becker K and Langer R: MicroRNA expression profiling for the prediction of resistance to neoadjuvant radiochemotherapy in squamous cell carcinoma of the esophagus. J Transl Med 16: 109, 2018.

21. Betel D, Wilson M, Gabow A, Marks DS and Sander C: The microRNA.org resource: Targets and expression. Nucleic Acids Res 36 (Database issue): D149-D153, 2008.

22. Vellayappan BA, Soon YY, Ku GY, Leong CN, Lu JJ and Tey JC: Chemoradiotherapy versus chemoradiotherapy plus surgery for esophageal cancer. Cochrane Database Syst Rev 8: CD010511, 2017.

23. Kidane B, Coughlin S, Vogt K and Malthaner R: Preoperative chemotherapy for resectable thoracic esophageal cancer. Cochrane Database Syst Rev CD001556: 2015.

23. Hao X, Xia L, Qu R, Yang X, Jiang M and Zhou B: Association between miR-146a rs2910164 polymorphism and specific cancer susceptibility: An updated meta-analysis. Fam Cancer 17: 459-468, 2018.

24. Shi L, Xu Z, Wu G, Chen X, Huang Y, Wang Y, Jiang W and Ke B: Up-regulation of miR-146a increases the sensitivity of non-small cell lung cancer to DDP by downregulating cyclin J. BMC Cancer 17: 138, 2017.

25. Tan W, Liao Y, Qiu Y, Liu H, Tan D, Wu T, Tang M, Zhang S and Wang H: miRNA 146a promotes chemotherapy resistance in lung cancer cells by targeting DNA damage inducible transcript 3 (CHOP). Cancer Lett 428: 55-68, 2018.

26. Liao YQ, Liao YL, Li J, Peng LX, Wan YY and Zhong R: Polymorphism in miR-146a associated with clinical characteristics and outcomes in gastric cancer patients treated with adjuvant oxaliplatin and fluoropyrimidines. Onco Targets Ther 8: 2627-2633, 2015.

27. Xue L, Nan J, Dong L, Zhang C, Li H, Na R, He H and Wang Y: Upregulated miR-483-5p expression as a prognostic biomarker for esophageal squamous cell carcinoma. Cancer Biomark 19: 193-197, 2017.

28. Fan S, Chen WX, Lv XB, Tang QL, Sun LJ, Liu BD, Zhong JL, Lin ZY, Wang YY, Li QX, et al: miR-483-5p determines mitochondrial fission and cisplatin sensitivity in tongue squamous cell carcinoma by targeting FIS1. Cancer Lett 362: 183-191, 2015.

29. Cui XB, Peng H, Li RR, Mu JQ, Yang L, Li N, Liu CX, Hu JM, Li SG, Wei Y, et al: MicroRNA-34a functions as a tumor suppressor by directly targeting oncogenic PLCE1 in Kazakh esophageal squamous cell carcinoma. Oncotarget 8: 92454-92469, 2017.

30. Song C, Lu P, Sun G, Yang L, Wang Z and Wang Z: miR-34a sensitizes lung cancer cells to cisplatin via p53/miR-34a/ MYCN axis. Biochem Biophys Res Commun 482: 22-27, 2017.

31. Sun C, Wang FJ, Zhang HG, Xu XZ, Jia RC, Yao L and Qiao PF: miR-34a mediates oxaliplatin resistance of colorectal cancer cells by inhibiting macroautophagy via transforming growth factor- $\beta$ / Smad4 pathway. World J Gastroenterol 23: 1816-1827, 2017.

32. Zhang Q, Wang J, Li N, Liu Z, Chen Z, Li Z, Lai Y, Shen L and Gao J: miR-34a increases the sensitivity of colorectal cancer cells to 5-fluorouracil in vitro and in vivo. Am J Cancer Res 8: 280-290, 2018

33. Xue L, Yu X, Jiang X, Deng X, Mao L, Guo L, Fan J, Fan Q, Wang L and Lu SH: TM4SF1 promotes the self-renewal of esophageal cancer stem-like cells and is regulated by miR-141. Oncotarget 8: 19274-19284, 2017.

34. Wang F, Zhao L, Zhang J, Meng Z, Zhou C, Wang G, Liu Y, Li M, Xi J, Niu W and Wang G: Chemotherapy-induced miR-141/ MAP4K4 signaling suppresses progression of colorectal cancer. Biosci Rep 38: BSR20180978, 2018.

35. Li S, Zhu J, Li J, Li S and Li B: MicroRNA-141 inhibits proliferation of gastric cardia adenocarcinoma by targeting MACC1. Arch Med Sci 14: 588-596, 2018. 
36. Fang S, Zeng X, Zhu W, Tang R, Chao Y and Guo L: Zinc finger E-box-binding homeobox 2 (ZEB2) regulated by miR-200b contributes to multi-drug resistance of small cell lung cancer. Exp Mol Pathol 96: 438-444, 2014.

37. Yu H, Duan B, Jiang L, Lin M, Sheng H, Huang J and Gao H: Serum miR-200c and clinical outcome of patients with advanced esophageal squamous cancer receiving platinum-based chemotherapy. Am J Transl Res 6: 71-77, 2013

38. Heydari K, Saidijam M, Sharifi MR, Dermani FK, Soleimani Asl S, Shabab N and Najafi R: The effect of miR-200c inhibition on chemosensitivity (5-FluoroUracil) in colorectal cancer. Pathol Oncol Res 24: 145-151, 2018.

39. Hur K, Toiyama Y, Takahashi M, Balaguer F, Nagasaka T, Koike J, Hemmi H, Koi M, Boland CR and Goel A: MicroRNA-200c modulates epithelial-to-mesenchymal transition (EMT) in human colorectal cancer metastasis. Gut 62: 1315-1326, 2013.
40. Diaz T, Tejero R, Moreno I, Ferrer G, Cordeiro A, Artells R, Navarro A, Hernandez R, Tapia G and Monzo M: Role of miR-200 family members in survival of colorectal cancer patients treated with fluoropyrimidines. J Surg Oncol 109: 676-683, 2014.

41. Hezova R, Kovarikova A, Srovnal J, Zemanova M, Harustiak T, Ehrmann J, Hajduch M, Sachlova M, Svoboda M and Slaby O: MiR-205 functions as a tumor suppressor in adenocarcinoma and an oncogene in squamous cell carcinoma of esophagus. Tumour Biol 37: 8007-8018, 2016.

42. Pan F, Mao H, Bu F, Tong X, Li J, Zhang S, Liu X, Wang L, Wu L, Chen R, et al: Spl-mediated transcriptional activation of miR-205 promotes radioresistance in esophageal squamous cell carcinoma. Oncotarget 8: 5735-5752, 2017. 